\title{
Measurement of CPAS Main Parachute Rate of Descent
}

\author{
Eric S. Ray ${ }^{1}$ \\ Jacobs ESCG, Houston, TX, 77598
}

\begin{abstract}
The Crew Exploration Vehicle Parachute Assembly System (CPAS) is being designed to land the Orion Crew Module (CM) at a safe rate of descent at splashdown. Flight test performance must be measured to a high degree of accuracy to ensure this requirement is met with the most efficient design possible. Although the design includes three CPAS Main parachutes, the requirement is that the system must not exceed $33 \mathrm{ft} / \mathrm{s}$ under two Main parachutes, should one of the Main parachutes fail. Therefore, several tests were conducted with clusters of two Mains. All of the steady-state rate of descent data are normalized to standard sea level conditions and checked against the limit. As the Orion design gains weight, the system is approaching this limit to within measurement precision. Parachute "breathing," cluster interactions, and atmospheric anomalies can cause the rate of descent to vary widely and lead to challenges in characterizing parachute terminal performance. An early test had contradictory rate of descent results from optical trajectory and Differential Global Positioning Systems (DGPS). A thorough analysis of the data sources and error propagation was conducted to determine the uncertainty in the trajectory. It was discovered that the Time Space Position Information (TSPI) from the optical tracking provided accurate position data. However, the velocity from TPSI must be computed via numerical differentiation, which is prone to large error. DGPS obtains position through pseudo-range calculations from multiple satellites and velocity through Doppler shift of the carrier frequency. Because the velocity from DGPS is a direct measurement, it is more accurate than TSPI velocity. To remedy the situation, a commercial off-the-shelf product that combines GPS and an Inertial Measurement Unit (IMU) was purchased to significantly improve rate of descent measurements. This had the added benefit of solving GPS dropouts during aircraft extraction. Statistical probability distributions for CPAS Main parachute rate of descent and drag coefficient were computed and plotted. Using test data, a terminal rate of descent at splashdown can be estimated as a function of canopy loading.
\end{abstract}

\section{Nomenclature}

$\begin{array}{lll}\mathrm{BET} & =\text { Best Estimate Trajectory } & \\ \mathrm{C}_{\mathrm{D}} & =\text { Drag coefficient } & \\ \mathrm{C}_{\mathrm{D}_{\mathrm{o}}} & = & \text { Drag coefficient related to full open canopy, normalized to suspended weight by convention } \\ \left(\mathrm{C}_{\mathrm{D}} \mathrm{S}\right)_{\text {Payload }} & =\text { Effective drag area of payload or test vehicle } & \\ \mathrm{CDT} & =\text { Cluster Development Test (series) } & \text { To do: } \\ \mathrm{CEP} & =\text { Circular Error Probable } & \text { Condense to eliminate } \\ \mathrm{CEV} & =\text { Crew Exploration Vehicle } & \text { white-space between } \\ \mathrm{CM} & =\text { Crew Module } & \text { sections } \\ \mathrm{CORS} & =\text { Continuously Operating Reference System } & \\ \mathrm{CPAS} & =\text { Crew Exploration Vehicle Parachute Assembly System } & \\ \Delta, \text { delta } & =\text { Uncertainty in a measurement or calculated value } & \\ \mathrm{DGPS} & =\text { Differential Global Positioning System } & \\ \mathrm{D}_{\mathrm{o}} & =\text { Nominal parachute diameter based on constructed area, } \mathrm{D}_{\mathrm{o}}=\sqrt{4 \cdot \mathrm{S}_{\mathrm{o}} / \pi} \\ \mathrm{DOP} & =\text { Dilution Of Precision } & \\ \mathrm{EDU} & =\text { Engineering Development Unit }\end{array}$

\footnotetext{
${ }^{1}$ Analysis Engineer, Aerothermal and Flight Mechanics, 455 E. Medical Center Blvd., Webster, TX, AIAA
} Member. 


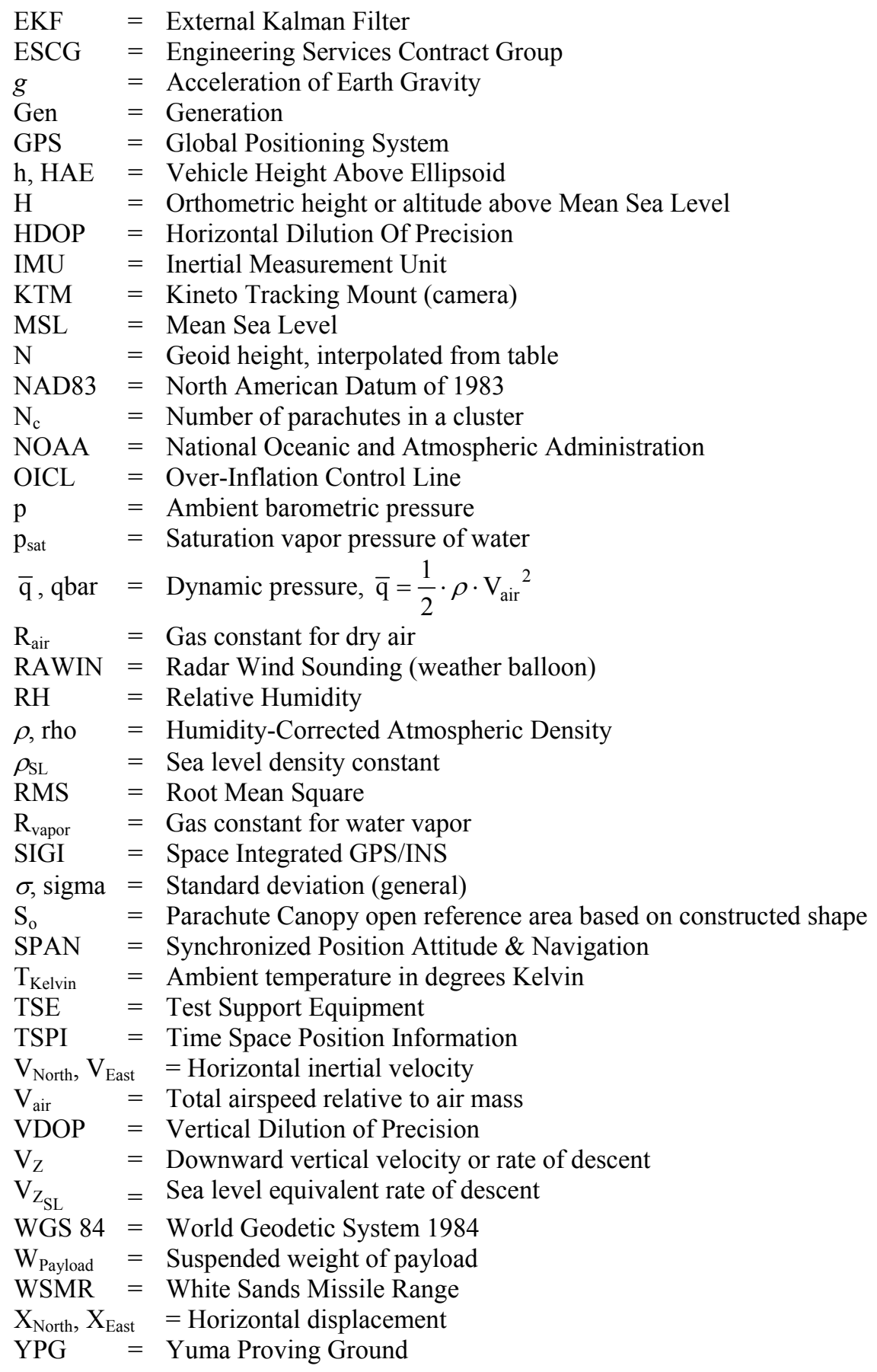

\section{Introduction}

$\mathrm{T}$ HE Crew Exploration Vehicle Parachute Assembly System (CPAS) is required to safely land the Orion Crew Module (CM) at a rate of descent not to exceed 33 feet per second at sea level on a standard day. A series of flight tests are being conducted to test the design against this requirement. A Generation (Gen) I test called CDT-3 appeared to possibly break this limit, depending on which data source was used. Any additional parachute material would add mass to Orion, and cascade into the entire launch architecture at considerable cost. A thorough analysis of the accuracy of each data source was therefore warranted to determine whether the requirement was met, 
especially as the baseline Orion design gained mass. The program strives to minimize CPAS mass necessary to meet requirements.

All tests discussed here were conducted at the Robby Drop Zone (DZ) at Yuma Proving Ground (YPG) in Yuma, AZ, ${ }^{*}$ except for the Pad Abort One test at White Sands Missile Range (WSMR) in New Mexico. Each test was a cluster of two or three CPAS Main quarter spherical ringsail parachutes with a reference diameter, $\mathrm{D}_{\mathrm{o}}$, of 116 $\mathrm{ft}$. By normalizing Main steady-state data to a standard day at sea level, CPAS can take advantage of all the valid data collected for similar tests. Given enough time, a functioning parachute system will "forget" its initial state, and the system can be defined as ergodic. Under this assumption, the velocity at test vehicle touchdown has no more predictive value than any other relevant instant. In fact, the tests were conducted in a desert environment with different ground effects than the ocean.

The steady-state drag coefficient and rate of descent vary considerably during the Main parachute phase due to parachute "breathing," cluster interaction, and atmospheric anomalies such as updrafts and wind gusts. Therefore, understanding parachute performance involves a combination of improved fidelity of modeling and a large base of tests from which to draw statistics.

\section{Data Reduction Method}

A flow diagram of the typical test data process is shown in Figure 1. Information is first assembled into "Best Estimate" Atmosphere, Wind, and Trajectory files. This paper will focus on the steady-state performance output parameters.

The data reduction process also propagates instrumentation uncertainty through to calculated parameters. Each resulting function, y, from $n$ uncorrelated measured variables, $\mathrm{x}_{\mathrm{i}}$, can be organized in the form of Eq. (1). The uncertainty estimate, $\Delta y$, is then calculated according to Eq. (2), where the uncertainty in each measurement, $\Delta \mathrm{x}_{\mathrm{i}}$, is multiplied by the partial derivative of the function with respect to that variable. The root sum of the squares

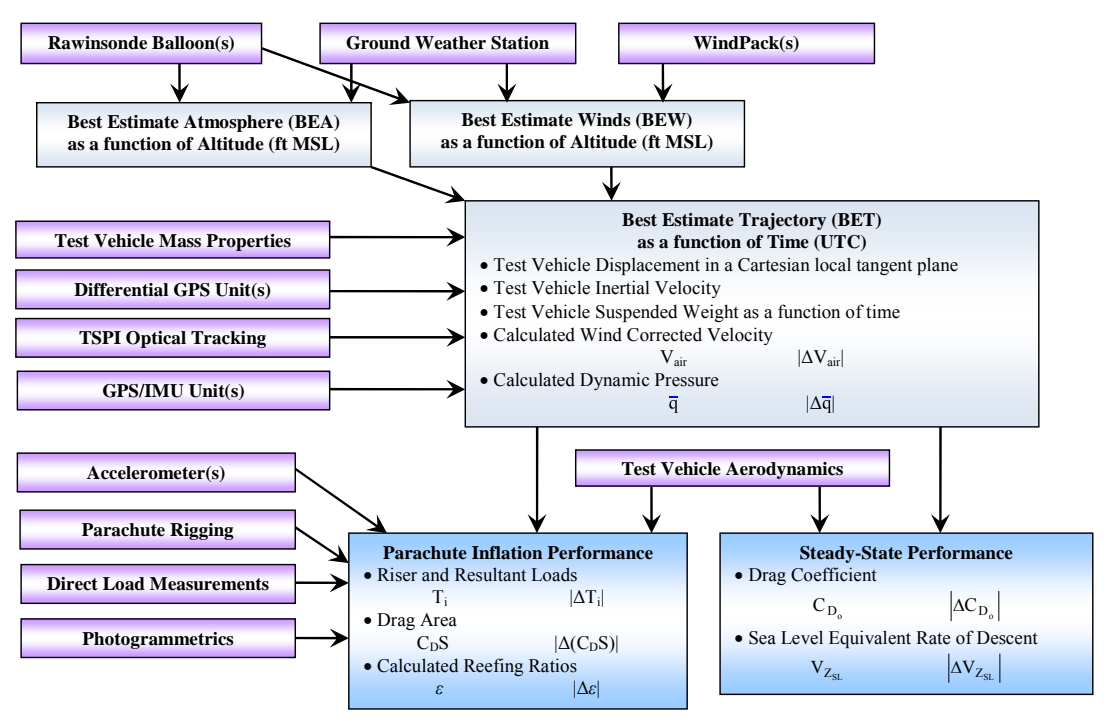

Figure 1. Data Post-Processing Overview.

is taken for each variable to compute the propagated uncertainty. ${ }^{(1)}$ For consistency, all uncertainties are calculated at a $95 \%$ probability.

$$
\begin{gathered}
y=f\left(x_{1}, x_{2}, \ldots x_{n}\right) \\
|\Delta y|=\left[\sum_{i=1}^{n}\left(\Delta x_{i} \cdot \frac{\partial y}{\partial x_{i}}\right)^{2}\right]^{1 / 2}
\end{gathered}
$$

\section{A. Position and Inertial Velocity}

The vertical position of the test article at any time will need to be converted to Mean Sea Level (MSL) to relate to atmospheric data from external sources. Aerodynamic vehicle and parachute performance are defined in terms of airspeed relative to the air mass. However, most velocity measurements are made relative to an inertial frame. Local winds will therefore have to be estimated and subtracted out from inertial velocity.

* The DZ is referred to as Robby when the aircraft flies Northward, as was the case in all these tests, or as La Posa if the aircraft flies Southward. 


\section{Global Positioning System (GPS)}

GPS altitude measurements are usually recorded as a Height Above Ellipsoid (HAE), h. In order to convert to an orthometric height or Mean Sea Level (MSL), H, the local geoid height, N, must be subtracted from the HAE. This equation is illustrated in Figure 2. ${ }^{(2)}$ The geoid data were interpolated from tables at every point using databases and software obtained from NOAA. ${ }^{(3)}$ Throughout the conterminous U.S., the geoid lies

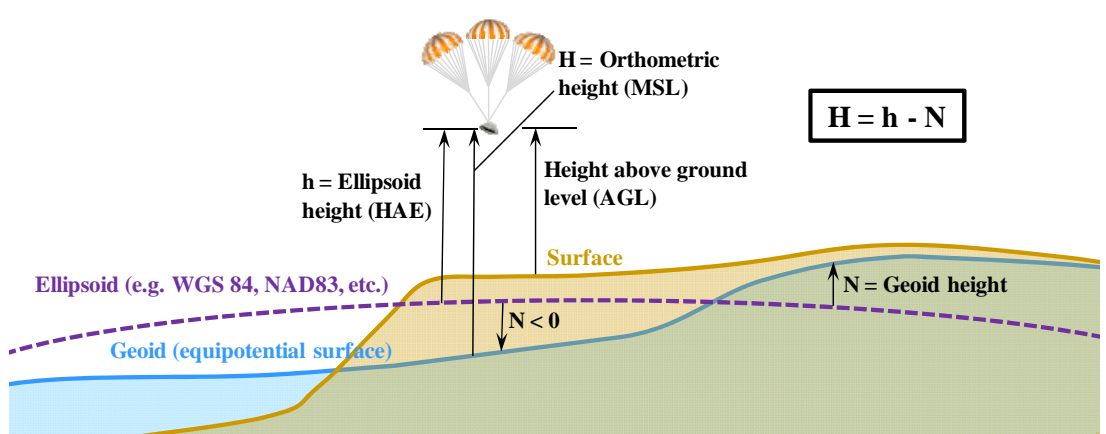

Figure 2. Conversion from Height Above Ellipsoid to Mean Sea Level. below the WGS 84 ellipsoid, so the geoid height is negative. ${ }^{(4)}$ The geoid height at YPG is approximately -33 meters or -100 feet but can vary by several meters based on the exact location.

The uncertainty of a GPS measurements are complex, which can be simplified by making some assumptions based on the system description for a typical test. GPS position is determined by "pseudorange" computations based on the time a signal travels and knowledge of the satellite position from orbital parameters. The uncertainty at a given instant is the product of the standard deviation of the pseudorange measurement error, $\sigma$, and a dimensionless term which depends on the satellite geometry called Dilution of Precision (DOP). The position error of each GPS device was reported by each manufacturer as a Circular Error Probable (CEP), which is defined as the radius of a horizontal circle which would contain the true position with a $50 \%$ probability. CEP uncertainty can be converted to a $95 \%$ probability by multiplying times $2.1 .^{(5)}$ Optimum satellite positioning may have a DOP of 1 , though values of 2 or 3 would be more common. DOP values of 5 or 6 are generally considered unacceptable for a GPS unit. The Vertical Dilution Of Precision (VDOP) is always higher than Horizontal Dilution Of Precision (HDOP) because the Earth blocks satellites that would be ideal for a vertical pseudorange estimate. VDOP can be assumed to be roughly twice HDOP ${ }^{(4)}$ In the absence of instant estimates, HDOP will be assumed to be 2 and VDOP will be assumed to be 4 for a GPS with satellite lock. The resulting horizontal position uncertainties are presented in Eq. (3) and Eq. (4), and altitude uncertainty is given in Eq. (5).

$$
\begin{gathered}
\left|\Delta \mathrm{X}_{\text {North }}\right|=2.1 \cdot \mathrm{CEP} \cdot \mathrm{HDOP} \\
\left|\Delta \mathrm{X}_{\text {East }}\right|=2.1 \cdot \mathrm{CEP} \cdot \mathrm{HDOP} \\
|\Delta \mathrm{H}|=2.1 \cdot \mathrm{CEP} \cdot \mathrm{VDOP}
\end{gathered}
$$

The YPG facility includes GPS ground stations to improve the position accuracy. The instantaneous measurements at known positions are used to calculate and subtract out the inherent errors of mobile GPS receivers using double differencing. This method is known as Differential GPS (DGPS). Any GPS receiver can act as ground station provided it is left stationary long enough to obtain a highly accurate position fix and that it be recording simultaneously with the mobile receivers. ${ }^{(6)}$ It is also possible to use the Continuously Operating Reference System (CORS) to improve the position solution. However, the nearest CORS station to the Robby DZ is about $40 \mathrm{~km}$ away, which is just on the edge of usability.

GPS may determine velocity by two different methods. The relative velocity between a satellite and receiver can be computed from observed Doppler shift of the signal frequency. Knowledge of the satellite orbit can then be used to compute inertial velocity. The velocity uncertainty for most GPS models using this method is reported as an RMS value which is equivalent to a single standard deviation probability of about $68 \%$. Multiplying the RMS value by 1.7 will convert it to a 95\% probability. ${ }^{(5)}$ The horizontal components of uncertainty are shown in Eq. (6) and Eq. (7). Although documentation is lacking on this subject, it is expected that vertical velocity uncertainty will be twice as high as horizontal uncertainty for the similar reasons as position uncertainty. The vertical velocity uncertainty calculation is given in Eq. (8). ${ }^{(4)}$ 


$$
\begin{gathered}
\left|\Delta \mathrm{V}_{\text {North }}\right|=1.7 \cdot\left|\Delta \mathrm{V}_{\mathrm{RMS}}\right| \\
\left|\Delta \mathrm{V}_{\text {East }}\right|=1.7 \cdot\left|\Delta \mathrm{V}_{\mathrm{RMS}}\right| \\
\left|\Delta \mathrm{V}_{\mathrm{Z}}\right|=3.4 \cdot\left|\Delta \mathrm{V}_{\mathrm{RMS}}\right|
\end{gathered}
$$

CPAS used redundant NovAtel Superstar II DGPS units for the test article in Generation I testing. These provide inertial position and velocity (using the Doppler shift method) at rates up to $5 \mathrm{~Hz} .^{(7)}$ Similar units are still used to track the parent aircraft, chase helicopter, and any Windpacks.

A second method is to use an Inertial Measurement Unit (IMU) to integrate accelerometer readings once for velocity and twice for position. An IMU is particularly useful in airborne parachute testing where the GPS solution is typically lost for about 30 seconds after the test vehicle is extracted from the parent aircraft. ${ }^{(8)}$ This happens as the GPS transitions from receiving a re-radiated signal inside the cabin to direct satellite observations. IMU errors will accumulate with time due to bias and drift. The optimal method is to regularly correct IMU propagation with GPS measurements. ${ }^{(9)}$ An IMU that runs without GPS updates may not provide a sufficient level of accuracy. ${ }^{(10)}$ An integrated GPS/IMU may provide position and velocity uncertainty estimates based upon the residuals of a Kalman filter.

Two models of integrated GPS/IMU were used by CPAS beginning with Generation II testing. The NovAtel SPAN-SE (Synchronized Position Attitude \& Navigation) is generally considered as "truth" for test vehicle position, velocity, and attitude. A Kalman filter in the post-processing software is used to continue position and velocity estimation during any GPS dropout. ${ }^{(11)}$ The attitude sensors use laser ring gyros which are not susceptible to magnetic interference of the metallic aircraft and payload, which is a common problem with other attitude sensors. ${ }^{(12)}$ Due to high unit cost, tests only use a single SPAN-SE on the test vehicle. Therefore, CPAS also began using several Crossbow NAV440 navigation systems as backup. Each NAV440 provides full inertial attitudes, angular rates, accelerations and GPS position. The velocity is "inertially derived" by integrating accelerometer readings. ${ }^{(13)}$ As a consequence, the velocity uncertainty is several times higher than GPS units that measure direct frequency phase shift measurements. 


\section{Time Space Position Information (TSPI)Optical Solution}

YPG has a series of fixed ground cameras on Kineto Tracking Mounts (KTM) which follow the test article or parent aircraft trajectory. The YPG Data Computation Team analyzes video from KTM cameras to determine a Time Space Position Information (TSPI) of payload and parent aircraft as a function of time. These are calculated from azimuth and elevations histories from each KTM boresight. The relative positions of the test vehicle center of mass are tracked manually in each video frame for precise azimuth and elevation fixes. A minimum of two perspectives are needed to compute the distance to the target at the intersection (or closest approach) of two rays. In practice, at least three KTM cameras are used to reduce error through a least squares method. Figure 3 shows the KTM locations at Robby Drop Zone (DZ). Four sample line-of-sight vectors between each KTM and target illustrate the azimuth readings, which are measured clockwise from North.

The TSPI heights and KTM elevation angles are illustrated in Figure 4. The best fit TSPI location of the target is

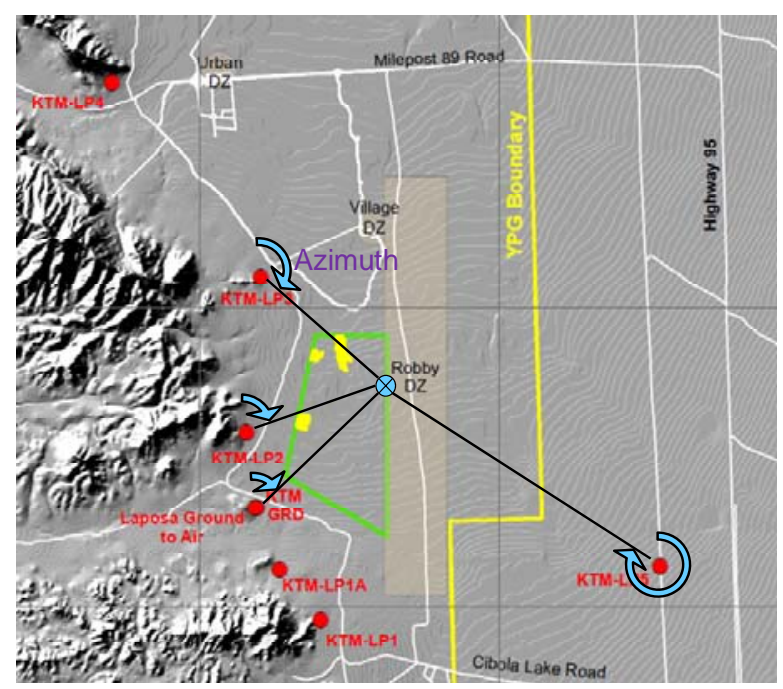

Figure 3. Sample azimuth readings from Robby DZ KTM location.

calculated in a Cartesian frame relative to a test origin which may change from test to test. Knowledge of the local datum is needed to convert the TSPI vertical coordinate to a height above mean sea level.

YPG takes care to minimize errors in the TSPI solution by performing regular surveys of the KTM locations and measuring the site elevation and azimuth bias contributions before each flight test. The reported TSPI solution is smoothed to reduce noise. The unsmoothed minimum error coordinates at each time are recorded in the TSPI "Odle solution." This also records residuals in azimuth, elevation, and distance from each KTM. The residuals can be used to estimate position uncertainty through extensive trigonometry. The uncertainty in

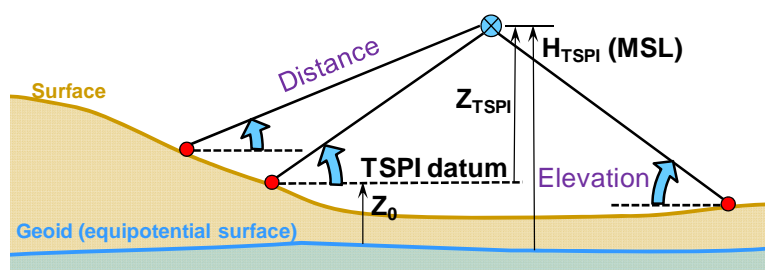

Figure 4. Sample KTM elevation readings. each reading for a given KTM will sweep out a wedge-shaped volume, which can be converted to Cartesian coordinates. The uncertainty readings from each KTM used on test CDT-1 are shown for a single point along the trajectory in Figure 5. The uncertainty volumes for some KTMs are larger than others. The smoothed TSPI trajectory solution is nearly identical to the Odle solution, while both are bracketed by two DGPS units on the load.

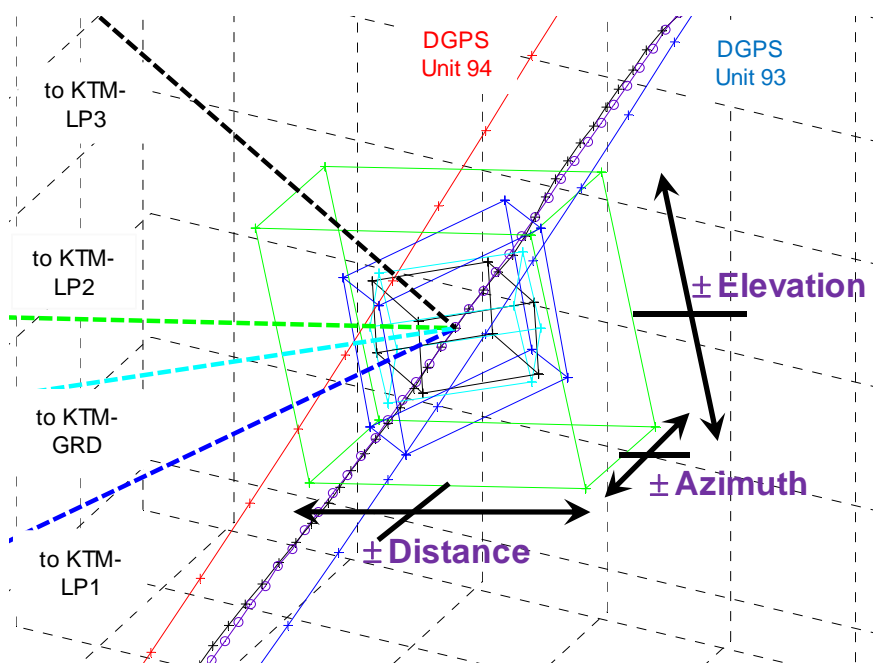

Figure 5. TSPI uncertainty volumes for CDT-1.

TSPI is generally an accurate measurement of test vehicle position and was the only available data source during each GPS dropout for Gen I tests. The first Gen II test to solve the dropout problem by using a GPS/IMU was called EDU-A-TSE-1A. The altitude measurements from each source for this test are compared in Figure 7 with vertical uncertainty estimates shown close up. The TSPI uncertainty is calculated as an average of the vertical uncertainties from each KTM, and can be seen to be more accurate than DGPS measurements. The SPAN-SE data is considered the best available data though the indicated error bars are overly conservative estimates based on the specification sheet, because the Kalman filter error estimates were not available for this test. There is also some small discrepancy in the datums used in post-processing each system.

The uncertainty bounds overlap, implying that a true physical solution is contained between them. 


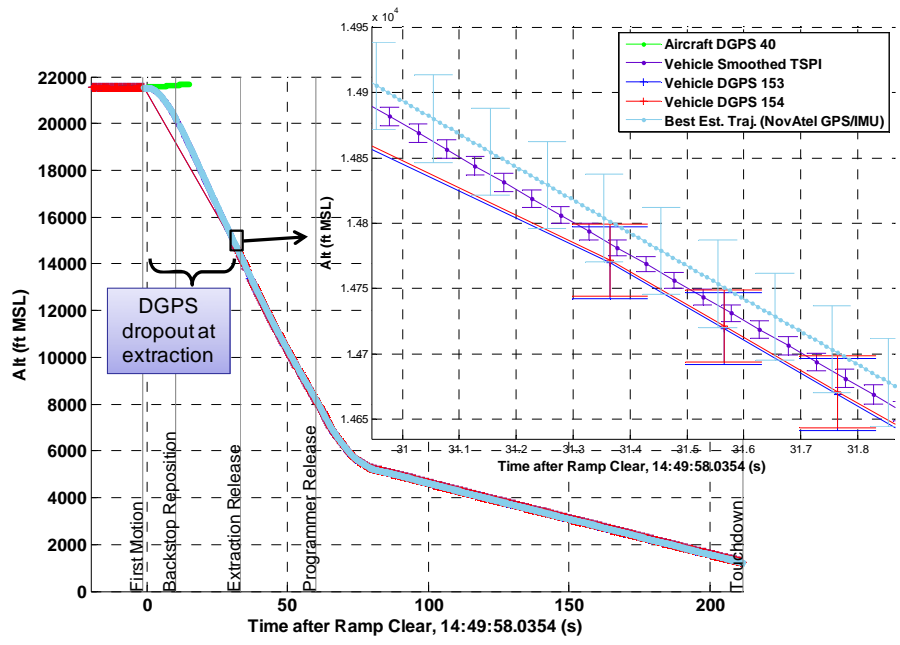

Figure 6. GPS and TSPI altitude for EDU-A-TSE-1A.

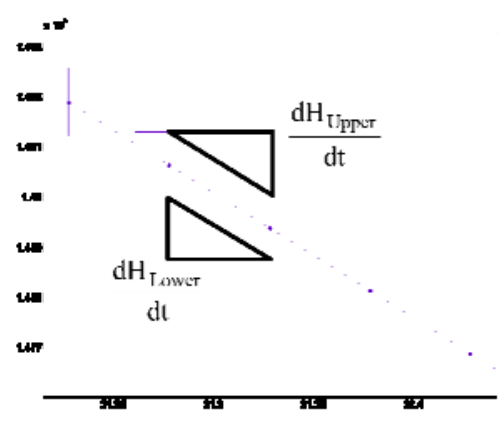

Figure 7. TSPI altitude and rate of descent uncertainty.

Despite its precision with position, TSPI is not the optimum method to compute velocity, because it

must be determined indirectly through numerical differentiation. The rate of descent from TSPI, for example, is the time rate of change of altitude. To reduce errors, a smoothed solution is taken through the nominal data. In the same way, two other solutions can be made by calculating the slopes through the minimum and maximum altitudes, as illustrated in Figure 7. The difference between these velocities can be used as a velocity uncertainty estimate at each point, using Eq. (9).

$$
\left|\Delta \mathrm{V}_{\mathrm{Z}}\right|=\frac{1}{2} \cdot\left|\frac{\mathrm{dH}_{\text {Upper }}}{\mathrm{dt}}-\frac{\mathrm{dH}_{\text {Lower }}}{\mathrm{dt}}\right|
$$

A sample of the downward velocity and error estimates from multiple data sources is shown in Figure 8 for test EDU-A-TSE-1A. The GPS/IMU tends to track well with both DGPS units. The uncertainty estimates for TSPI velocity are much larger than for the GPS systems. Further, the GPS systems tend to show a more damped trajectory, which is more realistic based on the physics of the situation. As with the earlier Gen I two-Main cluster test, the rate of descent from this test comes very close to the design limit, justifying the acquisition of the higher accuracy system to optimize the design.

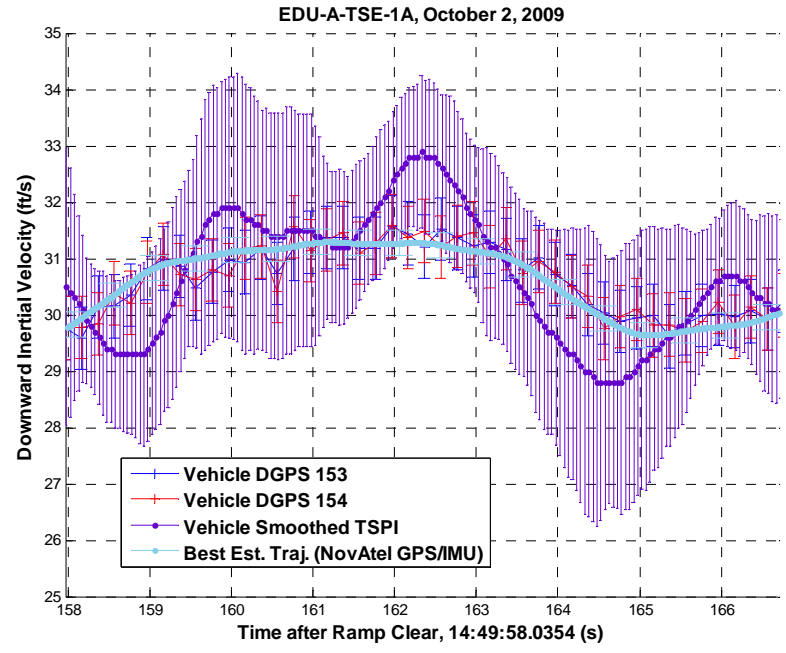

Figure 8. Vertical velocity comparison for EDU-A-TSE-1A. 


\section{B. Atmospheric Measurements}

In order to compare Main parachute steady-state performance across the entire altitude range within a test or from one test to another, the data are normalized to sea level equivalent conditions based on ambient atmospheric measurements. These measurements are provided by Radar Wind Sounding (RAWIN) balloons and a ground weather station. The uncertainty of the atmospheric measurements is combined with the uncertainty of the inertial velocity measurements through a series of uncertainty propagation equations. Temperature, $T$, static pressure, $\mathrm{p}$, and relative humidity, $\mathrm{RH}$, are directly measured to calculate ambient air density, $\rho$. The saturation pressure, $\mathrm{p}_{\text {sat }}$, is first determined with Eq. (10) where the temperature must be in Kelvin and the result is in mb. The uncertainty in saturation pressure is given by Eq. (11). The humidity-corrected density is computed in Eq. (12). Using the four independent variables $\mathrm{p}, \mathrm{RH}, \mathrm{p}_{\mathrm{sat}}$, and $\mathrm{T}$, the uncertainty is computed by taking the partial derivative of the density equation with respect to each, according to Eq. (2), which simplifies to Eq. (13).

$$
\begin{aligned}
& \mathrm{p}_{\text {sat }}=6.1078 \cdot 10^{\left(\frac{7.5 \cdot \mathrm{T}_{\text {Kelvin }}-2048.625}{\mathrm{~T}_{\text {Kelvin }}-35.85}\right)} \\
& \left|\Delta \mathrm{p}_{\text {sat }}\right|=\mid \mathrm{p}_{\text {sat }}\left(\mathrm{T}_{\text {Kelvin }}+|\Delta \mathrm{T}|\right)-\mathrm{p}_{\text {sat }}\left(\mathrm{T}_{\text {Kelvin }}-|\Delta \mathrm{T}|\right) \\
& \rho=\frac{\mathrm{p}-\mathrm{RH} \cdot \mathrm{p}_{\mathrm{sat}}}{\mathrm{R}_{\mathrm{air}} \cdot \mathrm{T}}+\frac{\mathrm{RH} \cdot \mathrm{p}_{\mathrm{sat}}}{\mathrm{R}_{\mathrm{vapor}} \cdot \mathrm{T}} \\
& |\Delta \rho|=\left[\left(\frac{|\Delta \mathrm{p}|}{\mathrm{R}_{\text {air }} \cdot \mathrm{T}}\right)^{2}+\left(|\Delta \mathrm{RH}| \cdot\left(\frac{-\mathrm{p}_{\text {sat }}}{\mathrm{R}_{\text {air }} \cdot \mathrm{T}}+\frac{\mathrm{p}_{\text {sat }}}{\mathrm{R}_{\text {vapor }} \cdot \mathrm{T}}\right)\right)^{2}+\left(\left|\Delta \mathrm{p}_{\text {sat }}\right| \cdot\left(\frac{-\mathrm{RH}}{\mathrm{R}_{\text {air }} \cdot \mathrm{T}}+\frac{\mathrm{RH}}{\mathrm{R}_{\text {vapor }} \cdot \mathrm{T}}\right)\right)^{2}+\left(\frac{|\Delta \mathrm{T}| \cdot \rho}{\mathrm{T}}\right)^{2}\right]^{1 / 2}
\end{aligned}
$$

\section{Steady-State Parachute Performance}

A single parachute is considered to be in steady-state descent when the drag force is equal to the payload weight. The force balance for a cluster is more complex, as illustrated in Figure 9. Steady-state can be determined when the test vehicle has first decelerated to $1 \mathrm{~g}$.

The primary source of the wind profiles are Windpacks. These are instrumented payloads suspended under very stable tri-lobe parachute system designed for a predictable equivalent rate of descent. Any horizontal displacement is attributed to the local wind field. ${ }^{(14)}$ Because the DGPS units in Windpacks experience a dropout at aircraft release, the RAWIN balloon data are used to fill in this gap. Ground station readings are also included in the Best Estimate Wind profile. Horizontal components of payload airspeed are computed by subtracting the horizontal wind components from the inertial velocity. Instantaneous updrafts and downdrafts are currently not measured due to their transient nature. The inertial vertical velocity and wind-corrected horizontal velocity are used to compute local airspeed, $\mathrm{V}_{\text {air }}$. Riser tension can be decomposed by measuring parachute fly-out angles relative to the geometric centroid. This allows for comparison with loads from an accelerometer.

Simplifications are used to compute the cluster steady-state drag coefficient in Eq. (14). The total parachute area is the number of

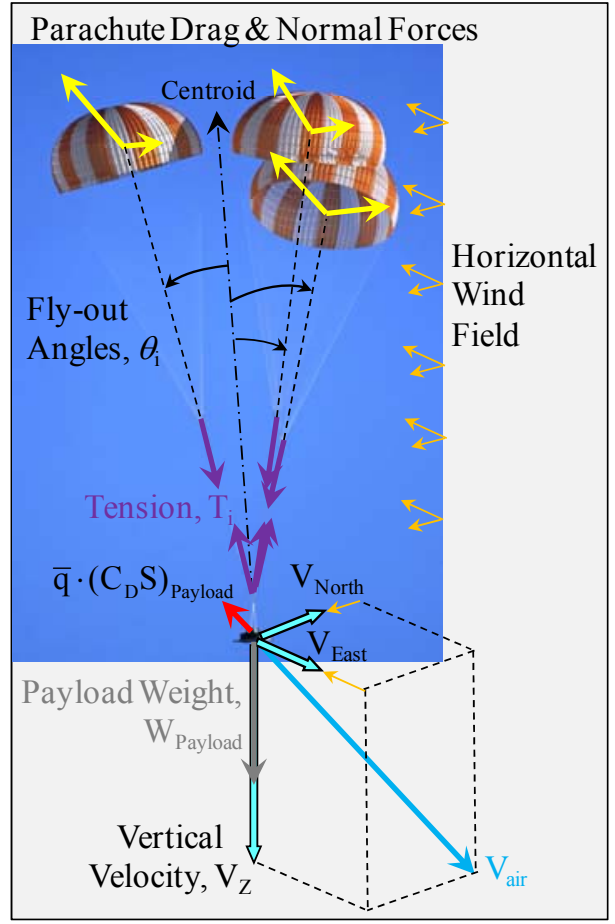

Figure 9. Parachute cluster diagram. 
parachutes in the cluster, $\mathrm{N}_{\mathrm{c}}$, multiplied by the reference diameter, $\mathrm{S}_{\mathrm{o}}$. By CPAS convention, the full open steadystate drag coefficient, $\mathrm{C}_{\mathrm{D}_{\mathrm{o}}}$, is normalized to the suspended weight of the payload, $\mathrm{W}_{\text {Payload, }}$, which does not include the weight of the parachute material and suspension equipment. The parachute steady-state drag coefficient is defined using purely vertical velocity, $\mathrm{V}_{Z}$, which neglects any parachute gliding motion. To isolate parachute drag, the drag area of the payload or vehicle, $\left(\mathrm{C}_{\mathrm{D}} \mathrm{S}\right)_{\text {Payload, }}$ must be subtracted from the system drag area.

$$
\mathrm{C}_{\mathrm{D}_{\mathrm{o}}}=\frac{1}{\mathrm{~N}_{\mathrm{c}} \cdot \mathrm{S}_{\mathrm{o}}} \cdot\left(\frac{\mathrm{W}_{\text {Payload }}}{\frac{1}{2} \cdot \rho \cdot \mathrm{V}_{\mathrm{Z}}^{2}}-\left(\mathrm{C}_{\mathrm{D}} \mathrm{S}\right)_{\text {Payload }}\right)
$$

Equation (14) has four independent variables: $\mathrm{W}_{\text {Payload }}, \mathrm{V}_{\mathrm{Z}}, \rho$, and $\left(\mathrm{C}_{\mathrm{D}} \mathrm{S}\right)_{\text {Payload. }}$ The partial derivative of the drag coefficient equation is taken with respect to each of these using the standard uncertainty analysis. This leads to the simplified drag coefficient uncertainty in Eq. (15).

$$
\left|\Delta \mathrm{C}_{\mathrm{D}_{\mathrm{o}}}\right|=\left[\left(\frac{2 \cdot\left|\Delta \mathrm{W}_{\text {Payload }}\right|}{\rho \cdot \mathrm{V}_{\mathrm{Z}}^{2} \cdot \mathrm{N}_{\mathrm{c}} \cdot \mathrm{S}_{\mathrm{o}}}\right)^{2}+\left(\frac{4 \cdot\left|\Delta \mathrm{V}_{\mathrm{Z}}\right| \cdot \mathrm{W}_{\text {Payload }}}{\rho \cdot \mathrm{V}_{\mathrm{Z}}^{3} \cdot \mathrm{N}_{\mathrm{c}} \cdot \mathrm{S}_{\mathrm{o}}}\right)^{2}+\left(\frac{2 \cdot|\Delta \rho| \cdot \mathrm{W}_{\text {Payload }}}{\rho^{2} \cdot \mathrm{V}_{\mathrm{Z}}^{2} \cdot \mathrm{N}_{\mathrm{c}} \cdot \mathrm{S}_{\mathrm{o}}}\right)^{2}+\left(\frac{\left|\Delta\left(\mathrm{C}_{\mathrm{D}} \mathrm{S}\right)_{\text {Payload }}\right|}{\mathrm{N}_{\mathrm{c}} \cdot \mathrm{S}_{\mathrm{o}}}\right)^{2}\right]^{1 / 2}
$$

Parachute rate of descent performance at altitude with varying atmospheric conditions are normalized to the sea level equivalent rate of descent, $\mathrm{V}_{\mathrm{Z}_{\mathrm{SL}}}$, for a standard day as defined in Eq. (16).

$$
\mathrm{V}_{\mathrm{Z}_{\mathrm{SL}}}=\mathrm{V}_{\mathrm{Z}} \cdot \sqrt{\frac{\rho}{\rho_{\mathrm{SL}}}}
$$

Uncertainty in equivalent rate of descent is computed according to Eq. (17). Uncertainty for both drag coefficient and equivalent rate of descent are most sensitive to vertical velocity, which is one of the reasons CPAS has invested in high quality GPS instrumentation. They are also both sensitive to density, which is not measured directly.

$$
\left|\Delta \mathrm{V}_{\mathrm{ZL}}\right|=\left[\left(\left|\Delta \mathrm{V}_{\mathrm{Z}}\right|^{2} \cdot \frac{\rho}{\rho_{\mathrm{SL}}}\right)+\left(|\Delta \rho|^{2} \cdot \frac{\mathrm{V}_{\mathrm{Z}}^{2}}{4 \cdot \rho_{\mathrm{SL}} \cdot \rho}\right)\right]^{1 / 2}
$$

The most important driver of rate of descent is the canopy loading, defined as the suspended weight divided by the total parachute surface area, $\mathrm{W}_{\text {payload }} /\left(\mathrm{N}_{\mathrm{c}} \cdot \mathrm{S}_{\mathrm{o}}\right)$. A summary of test results vs. canopy loading is presented in the conclusion.

Note that both $\mathrm{C}_{\mathrm{D}_{\mathrm{o}}}$ and $\mathrm{V}_{\mathrm{Z}_{\mathrm{SL}}}$ parameters are based on the same test data. Drag coefficient is proportional to the inverse square of equivalent rate of descent, so for a given test condition, a curve of approximately $\mathrm{Y}=1 / \mathrm{X}^{2}$ can be generated. Equations (14) and (16) can be combined to make the relation in Eq. (18).

$$
\mathrm{C}_{\mathrm{D}_{\mathrm{o}}}=\frac{1}{\mathrm{~N}_{\mathrm{c}} \cdot \mathrm{S}_{\mathrm{o}}} \cdot\left(\frac{\mathrm{W}_{\text {Payload }}}{\frac{1}{2} \cdot \rho_{\mathrm{SL}} \cdot\left(\mathrm{V}_{\mathrm{Z}_{\mathrm{SL}}}\right)^{2}}-\left(\mathrm{C}_{\mathrm{D}} \mathrm{S}\right)_{\text {Payload }}\right)
$$

CPAS parachute test data suggest that the distribution of sea level equivalent rate of descent data is Gaussian. If that is the case, then it follows from Eq. (18) that the corresponding distribution for drag coefficient is skewed with a peak probability density lower than the mean and a long tail towards high drag (or low rate of descent) end of the curve. Care must be taken when referring to statistical terms such as mean and standard deviation, which may not apply to drag coefficient. 


\section{Selected Flight Test Results}

Flight data are presented for selected CPAS tests, as well as the first Pad Abort test. Only tests with a cluster of Main parachutes using the baseline design are considered. CPAS Gen I and Gen II tests are summarized in Ref. (15) and Ref. (16), respectively. The results of additional design changes are discussed in separate papers.

\section{A. CDT-1}

CDT-1 was conducted on October 18, 2007. The test vehicle was a parachute compartment mockup mounted on a $9 \times 20 \mathrm{ft}$ Type V platform. Extraction from the C-130A occurred at about $10,930 \mathrm{ft}$ MSL where the system immediately deployed two CPAS Drogue parachutes. Pilot parachutes were mortar deployed to successfully extract the cluster of three Main parachutes already shown in Figure 9. Steady-state descent began at about 3,790 ft MSL and lasted for about 110 seconds. The suspended weight was set to approximate the Orion design at the time of 16,462 lb. With three Mains, the canopy loading was $0.519 \mathrm{lb} / \mathrm{ft}^{2}$.

A time history of the sea level equivalent rate of descent is shown in Figure 10. Due to the fairly low canopy loading, the system never approached the performance limit. The drag coefficient shown in Figure 11 showed an increasing trend. This is an artifact of reducing the data as if the airspeed was a purely vertical, when in fact the parachutes were gliding.

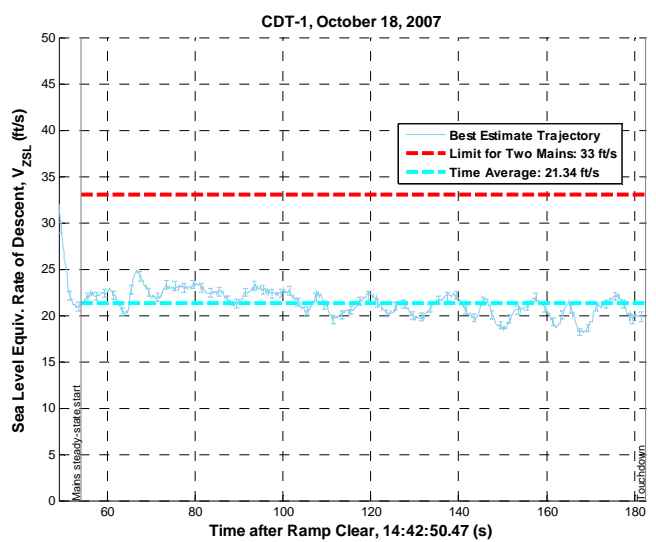

Figure 10. CDT-1 equivalent rate of descent. Further, a temperature inversion layer was encountered. This is due to the standard procedure of testing soon after dawn when winds are minimal, yet the desert floor begins warming.

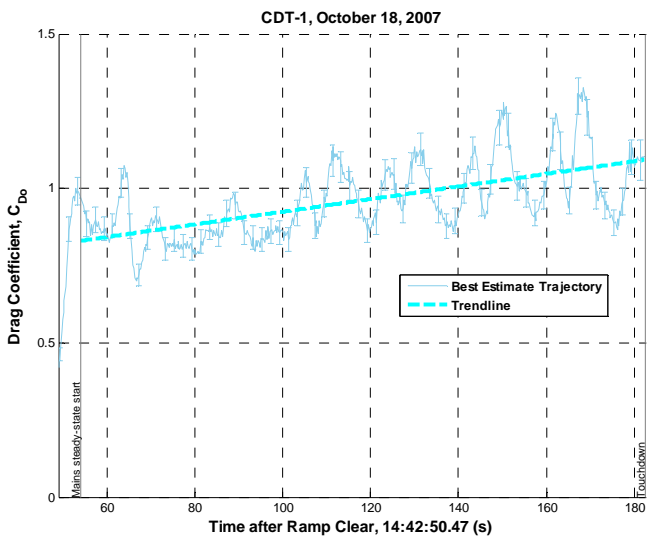

Figure 11. CDT-1 drag coefficient.

A statistical analysis of these data is presented in Figure 12. A histogram of equivalent rate of descent is shown in the upper right. The data were fit as a Gaussian curve, shown in black, to calculate a time average of $21.34 \mathrm{ft} / \mathrm{s}$ and standard deviation, $\sigma$, of $1.25 \mathrm{ft} / \mathrm{s}$. Bounds at the mean plus and minus $3 \sigma$ are indicated, which slightly exceed the minimum and maximum data actually encountered. These points are mapped to the drag coefficient histogram through the inverse square relationship plotted in the lower right. If the

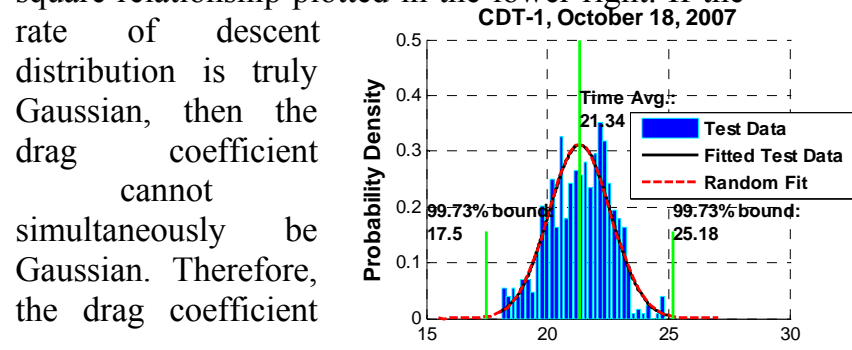

bounds are not described as $3 \sigma$, but as the equivalent probability of $99.73 \%$.

Randomized rate of descent data were generated using the calculated mean and standard deviation. This curve is plotted in red. These random data were then mapped to the drag coefficient histogram on the lower left and plotted as a red curve. This curve far better matches the drag coefficient distribution than attempting to fit drag
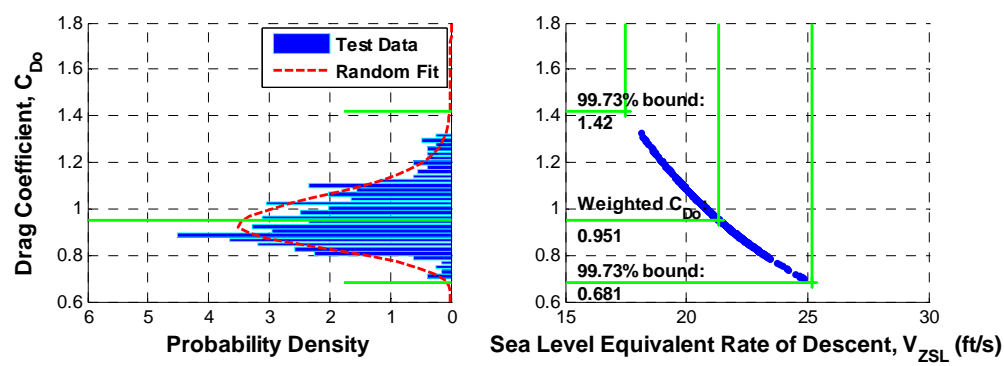

coefficient with a Gaussian Figure 12. CDT-1 steady-state performance histograms. distribution. 
The drag coefficient can be described as "right skewed," that is the highest probability density is lower than the time average and a long tail points toward high drag coefficient. The time average of drag coefficient is 0.962 , but the time average rate of rate of descent corresponds to 0.951 . Designing the parachute using the lower drag coefficient is the more conservative approach.

\section{B. CDT-3}

CDT-3 was conducted on June 17, 2008 and employed a cluster of two CPAS Mains seen in Figure 13. CPAS is required to meet the landing requirement with as few as two Mains, so several tests were conducted to drive the design with this limiting case. The test vehicle was a weight tub mounted on a $9 \times 20 \mathrm{ft}$ Type $\mathrm{V}$ platform. Extraction from the $\mathrm{C}$ $130 \mathrm{~A}$ occurred at about $18,100 \mathrm{ft}$ MSL where the system immediately deployed two CPAS Drogue parachutes. The Mains were deployed by static line as the Drogues cut away.

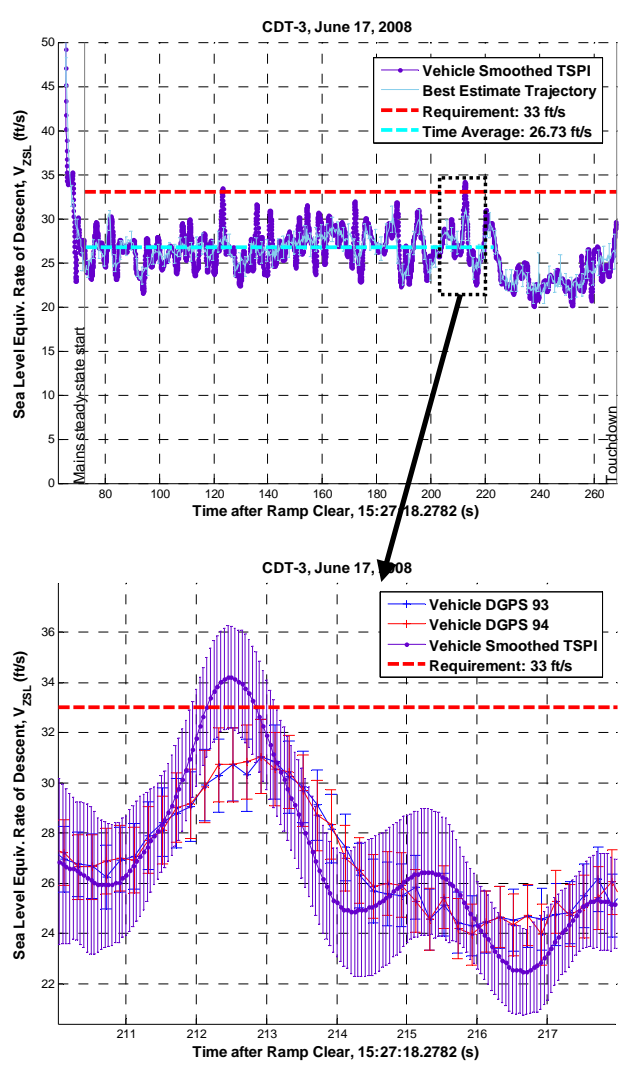

Figure 14. CDT-3 equivalent rate of descent.
Steady-state descent began at about $6,400 \mathrm{ft}$ MSL or about 130 seconds before touchdown. The suspended weight was about the same as CDT-1 at $16,717 \mathrm{lb}$ but the canopy loading was higher at 0.719 $\mathrm{lb} / \mathrm{ft}^{2}$ due to using one less Main. A strong temperature inversion layer was encountered at about $3,200 \mathrm{ft}$ MSL, and vertical winds were Figure 13. CDT-3 indicated by both Windpacks until the surface. The assumption of normalizing drag coefficient by the inertial vertical velocity breaks down when significant gliding or vertical winds are present. Therefore, statistics were only taken until about 223 seconds after ramp clear such that the time average rate of descent is $26.73 \mathrm{ft} / \mathrm{s}$.

The equivalent rate of descent is plotted in Figure 14. The nominal TSPI data exceeds the $33 \mathrm{ft} / \mathrm{s}$ limit on two occasions. The second of these occasions is shown in more detail for each of the raw data sources. The uncertainty of TSPI is consistently much higher than the uncertainty from DGPS readings. For most of the trajectory, there is overlap of these uncertainties, which validates the TSPI uncertainty estimate method and DGPS specification sheets. Therefore, the Best Estimate Trajectory (BET) is constructed from the average of the two DGPS units, neglecting the TSPI. This investigation indicates that the payload likely never actually broke the limit, and that the parachute design was successful. The corresponding Main steady-state drag coefficient is plotted in Figure 15. 


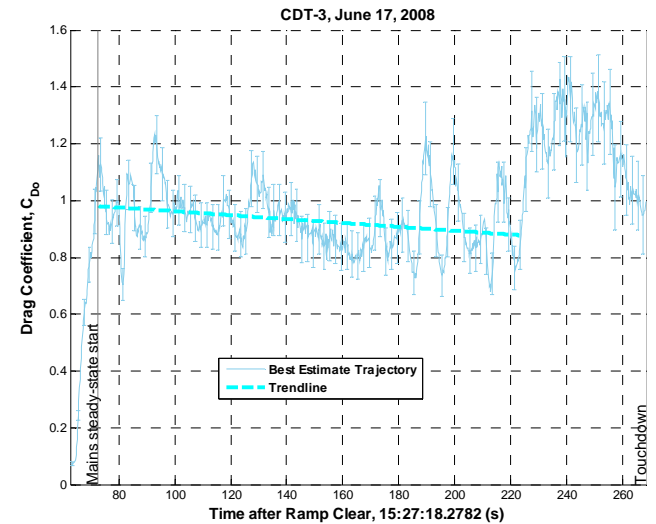

Figure 15. CDT-3 drag coefficient.

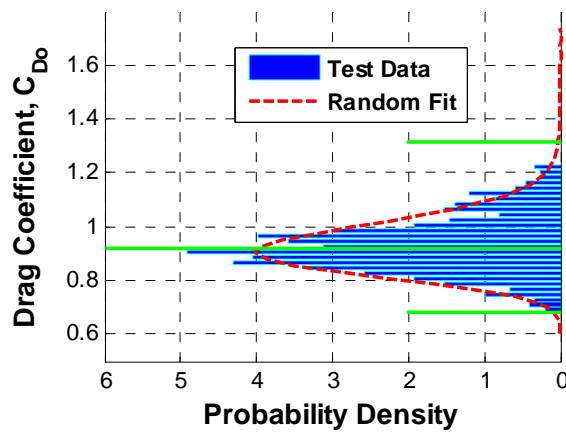

Histograms of steady-state performance are shown in Figure 16. Discounting the terminal data past encountering the inversion layer makes the histograms more Gaussian. The fitted standard deviation to rate of descent is $1.22 \mathrm{ft} / \mathrm{s}$ and the weighted drag coefficient is 0.921 .
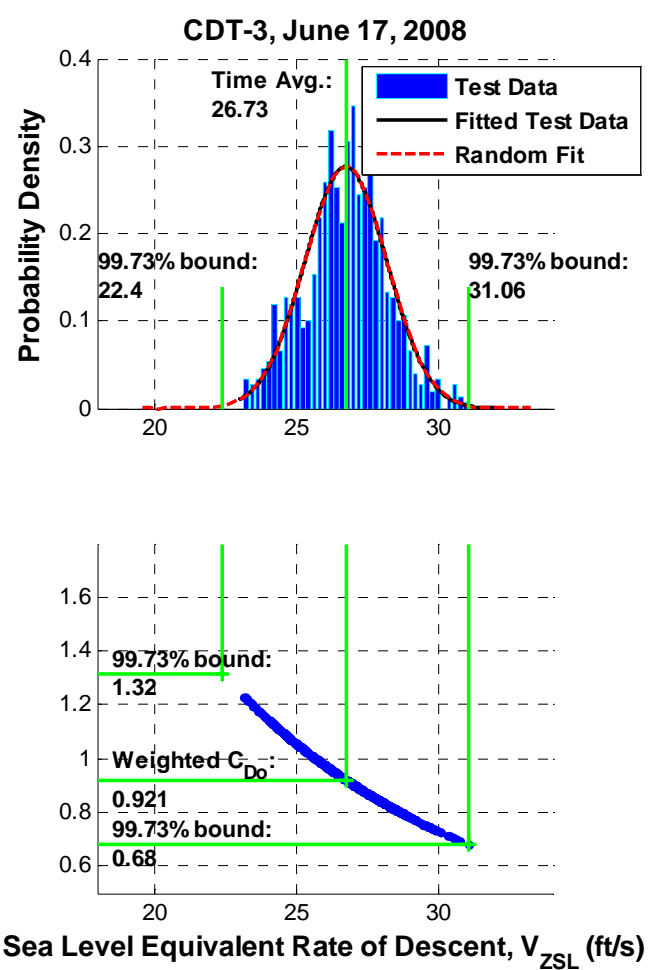

Figure 16. CDT-3 steady-state performance histograms. 


\section{EDU-A-TSE-1A}

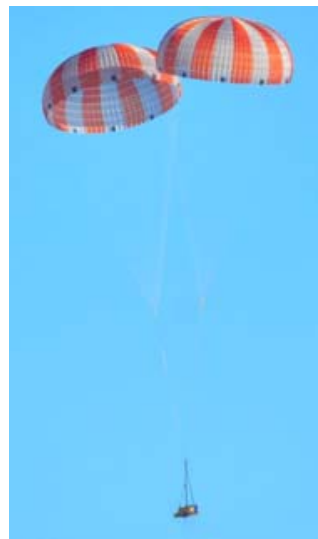

Figure 17. EDUA-TSE-1A Mains.
CPAS Generation II testing began with a series of flights named EDUA-TSE-1 or "smart release." The primary objectives dealt with avionics development but these tests were a good opportunity to get two-Main cluster performance as a secondary objective. EDU-A-TSE-1A was conducted on October 2, 2009. The smart release vehicle was a modified weight tub attached to a $9 \times 24 \mathrm{ft}$ Type $\mathrm{V}$ platform. Extraction from the C$130 \mathrm{~A}$ occurred at about $21,574 \mathrm{ft}$ MSL. A programmer parachute was deployed via a delayed load transfer to set up the test condition. A cluster of two Mains, seen in Figure 17, were static line deployed as the programmer cut away. Black dye markings were added to the skirt in an attempt to improve visibility for photogrammetrics. Each Main parachute also incorporated an Over-Inflation Control Line (OICL) which was intended to reduce the variation of rate of descent by limiting the inlet area.

The test article weight was chosen as $21,574 \mathrm{lb}$ to approximate the design Orion mass. The increased canopy loading of $0.909 \mathrm{lb} / \mathrm{ft} 2$ led to a higher time average rate of descent of $28.49 \mathrm{ft} / \mathrm{s}$ seen in Figure 18.

. On three occasions the nominal rate of descent from the NovAtel SPAN-SE approaches the $33 \mathrm{ft} / \mathrm{s}$ limit with uncertainty bands exceeding the limit twice. These sudden increases of descent rate, or sudden drops in drag coefficient in

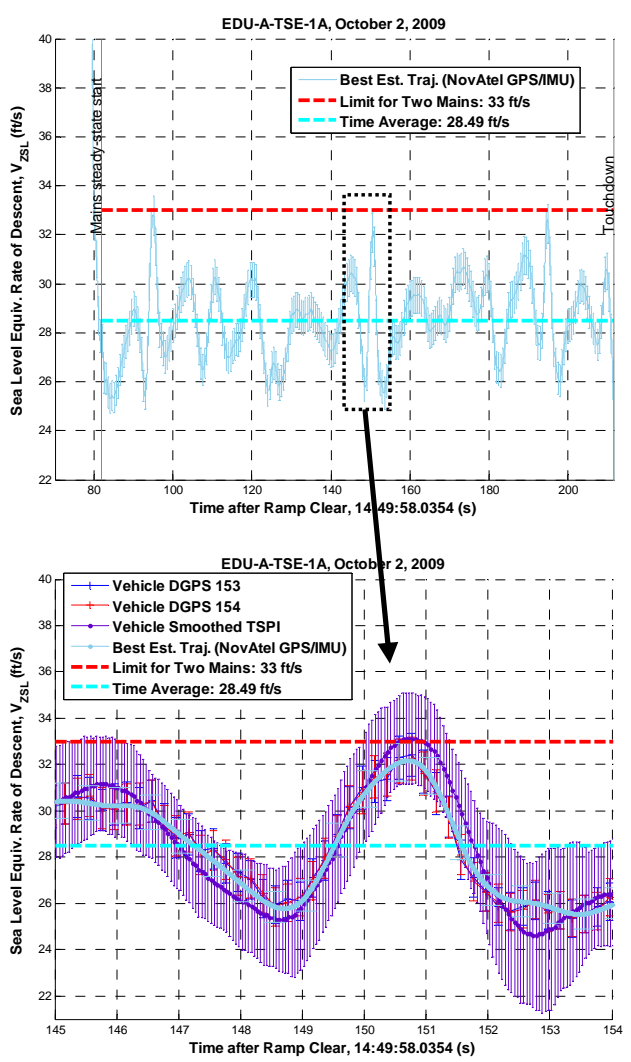

Figure 18. EDU-A-TSE-1A equivalent rate of descent.

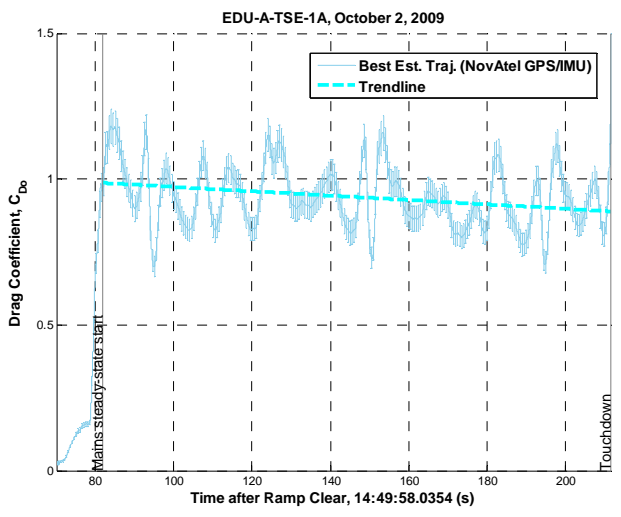

Figure 19. EDU-A-TSE-1A drag coefficient.

Figure 19, are due to relative instability of the cluster formation causing interference between the Mains. Like most of CDT-1, the drag coefficient for this test shows a slight downward trend.

The OICL had negligible effect on the amount of variation of rate of descent. The standard deviation of equivalent rate of descent for this test was $1.50 \mathrm{ft} / \mathrm{s}$, which was higher than the CDT-3 value of $1.44 \mathrm{ft} / \mathrm{s}$. A photogrammetric analysis showed that the skirt perimeter may never have completely opened to the OICL length.

A statistical analysis of these data is presented in Figure 20. A histogram of equivalent rate of descent is shown in the upper right. The standard deviation of the fitted rate of descent is $1.50 \mathrm{ft} / \mathrm{s}$. The flight test data does not actually encounter the mean plus and minus $3 \sigma$ equivalent values.

The randomized fit curves in red generally describe histograms. The typical right skew in the drag coefficient is not seen in this case as there were no exceptionally high drag data points. 

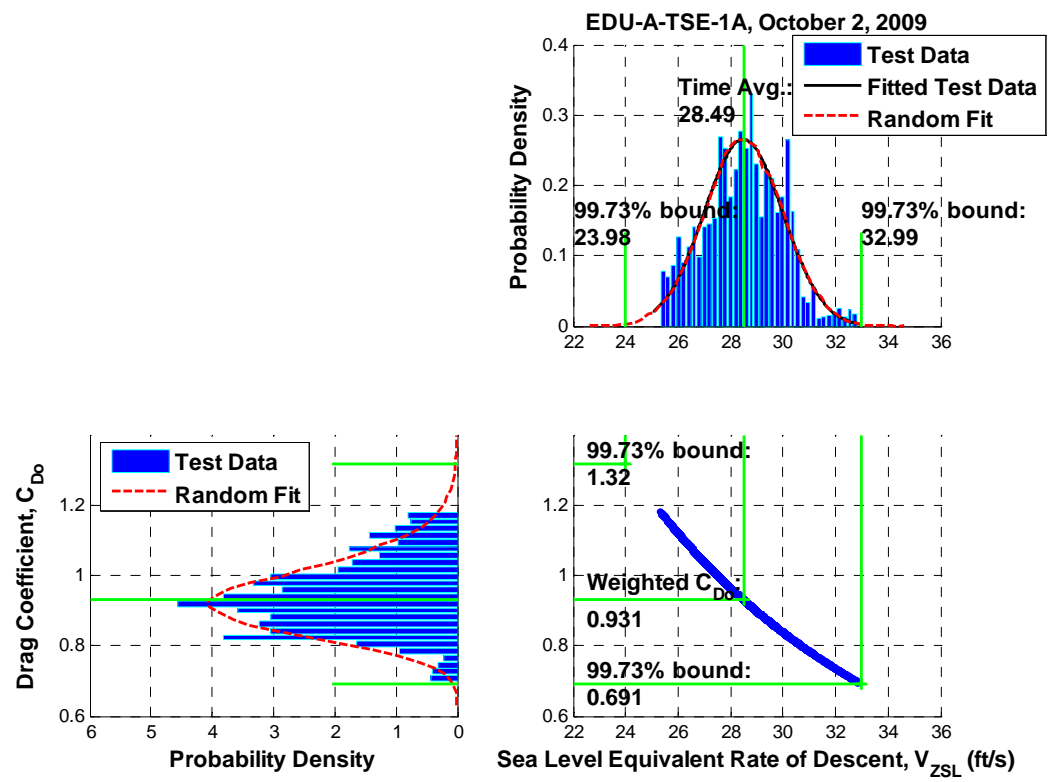

Figure 20. EDU-A-TSE-1A steady-state performance histograms. 


\section{EDU-A-TSE-1B}

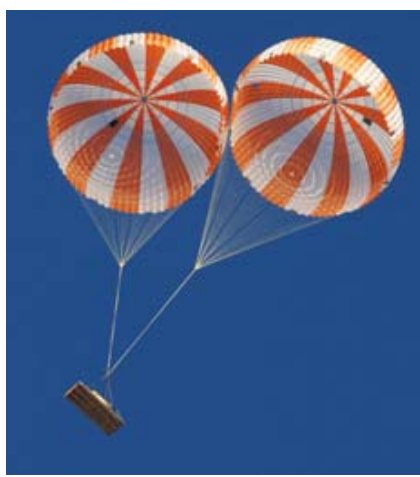

Figure 21. EDU-A-TSE1A Mains.
The second smart release test, EDU-A-TSE-1B was conducted on December 1, 2009. The same test vehicle and concept of operations was used as the previous test. Extraction from the C-130A occurred at about $21,175 \mathrm{ft}$ MSL. The cluster of two mains successfully deployed as seen in Figure 21. Additional black markings were added to different colored panels near the crown to aid in parachute identification of upward-looking video.

A time history of the sea level equivalent rate of descent is shown in Figure 22. The drag coefficient is shown in Figure 23. The high descent rate and low drag event near the $95 \mathrm{~s}$ mark was due to the parachutes flying out and crashing against each other, lowering the effective canopy surface area.

A statistical analysis of these data is presented in Figure 24. A histogram of equivalent rate of descent is shown

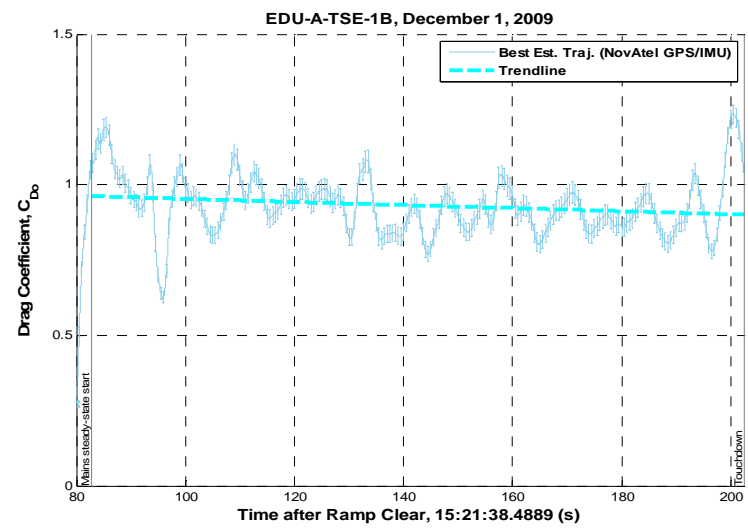
in the upper right. The data were fit as a Gaussian curve, shown in black, to calculate a time average of $28.56 \mathrm{ft} / \mathrm{s}$ and $\sigma$ of $1.44 \mathrm{ft} / \mathrm{s}$. The test data never went past the mean $\mathrm{V}_{\mathrm{Z}_{\mathrm{SL}}}$ $3 \sigma$ bound, but do exceed the mean $\mathrm{V}_{\mathrm{Z}_{\mathrm{SL}}}+3 \sigma$ bound due to the previously described event. The randomized red curves generally fit the shape of the histogram data with the exception of tail created by that region.

The time average of drag coefficient is 0.931 , but the time average rate of rate of descent

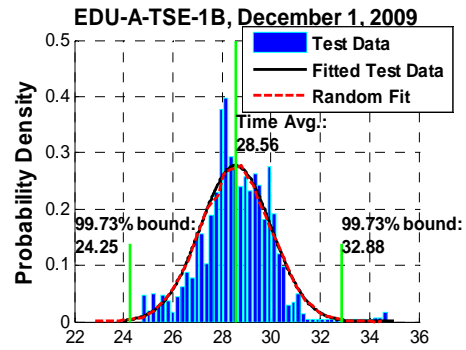

Figure 23. EDU-A-TSE-1B drag coefficient.

corresponds to a more conservative drag coefficient of 0.924 .
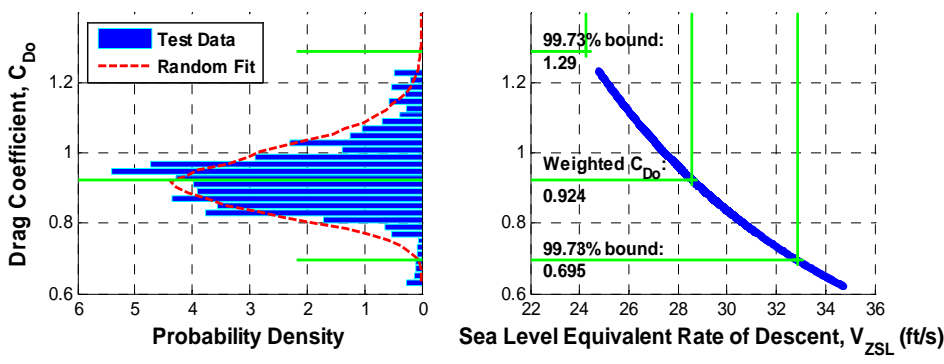

Figure 24. EDU-A-TSE-1B steady-state performance. 


\section{E. Pad Abort One}

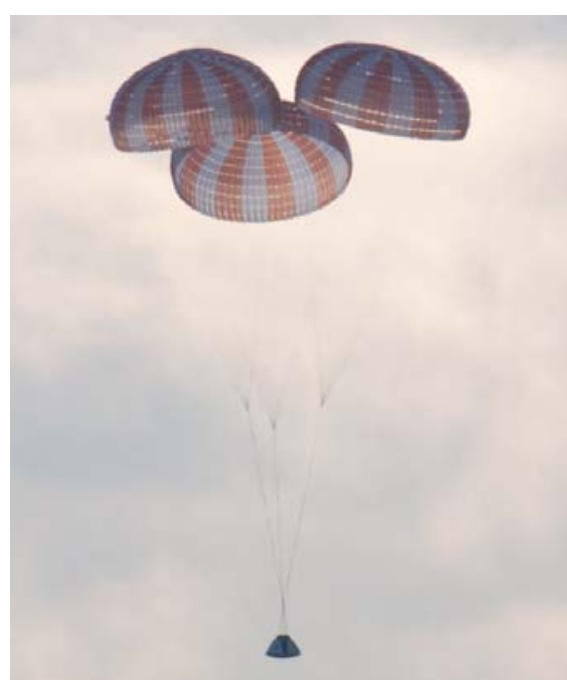

Figure 25. PA-1 Main parachutes.

The first Pad Abort demonstration test, PA-1, took place on May 6, 2010 at the White Sands Missile Range. A representative capsule shape ascended using the Launch Abort System (LAS) and descended under a sequence of CPAS parachutes, shown in Figure 25. The Generation I design meant the canopy loading under three Mains was only $0.5135 \mathrm{lb} / \mathrm{ft}^{2}$, lower than the Generation II cluster tests. Due to the relatively low altitude at parachute deployment, the time suspended under the Main parachutes was only about 74 seconds.

CPAS was not involved in the data collection for this test, but was provided a BET and atmosphere data. The prime source of navigation data from PA-1 came from sensed accelerations and angular rates in the Space Integrated GPS/INS (SIGI), provided by Honeywell. ${ }^{(17)}$ Other radar and optical data sources were combined with the SIGI data in an External Kalman Filter (EKF) to generate a BET. However, the system did not have a GPS receiver to correct inertial drift.

Due to its similarity with CDT-1, the steady-state results are compared to PA-1 in Figure 26 and Figure 27. Although the trends differ from CDT1 , the time average rate of descent is very similar at $21.69 \mathrm{ft} / \mathrm{s}$. The shorter time for steady-state statistics may have caused the data to be less Gaussian than other tests, as shown in the histograms of Figure 28.

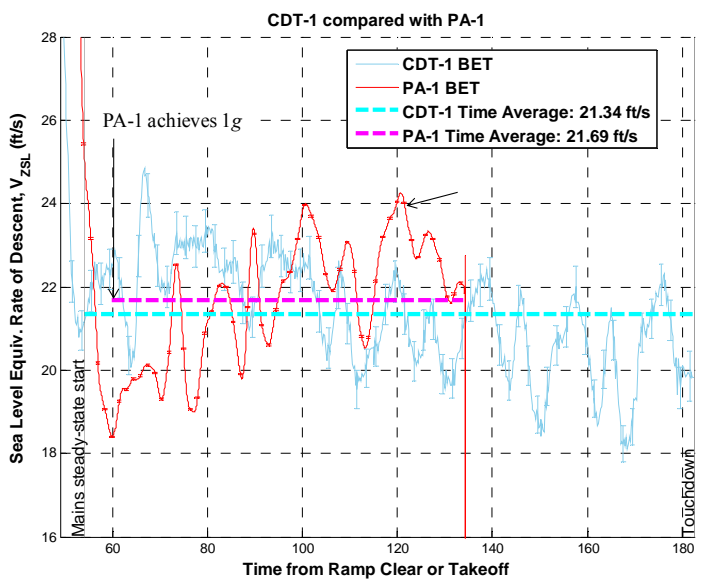

Figure 26. EDU-A-TSE-1B equivalent rate of descent.

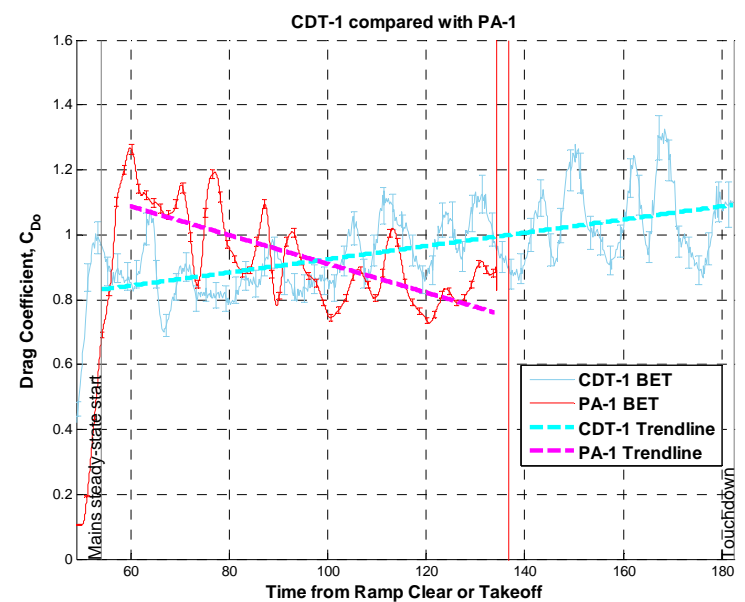

Figure 27. CDT-1 and PA-1 drag coefficient. 

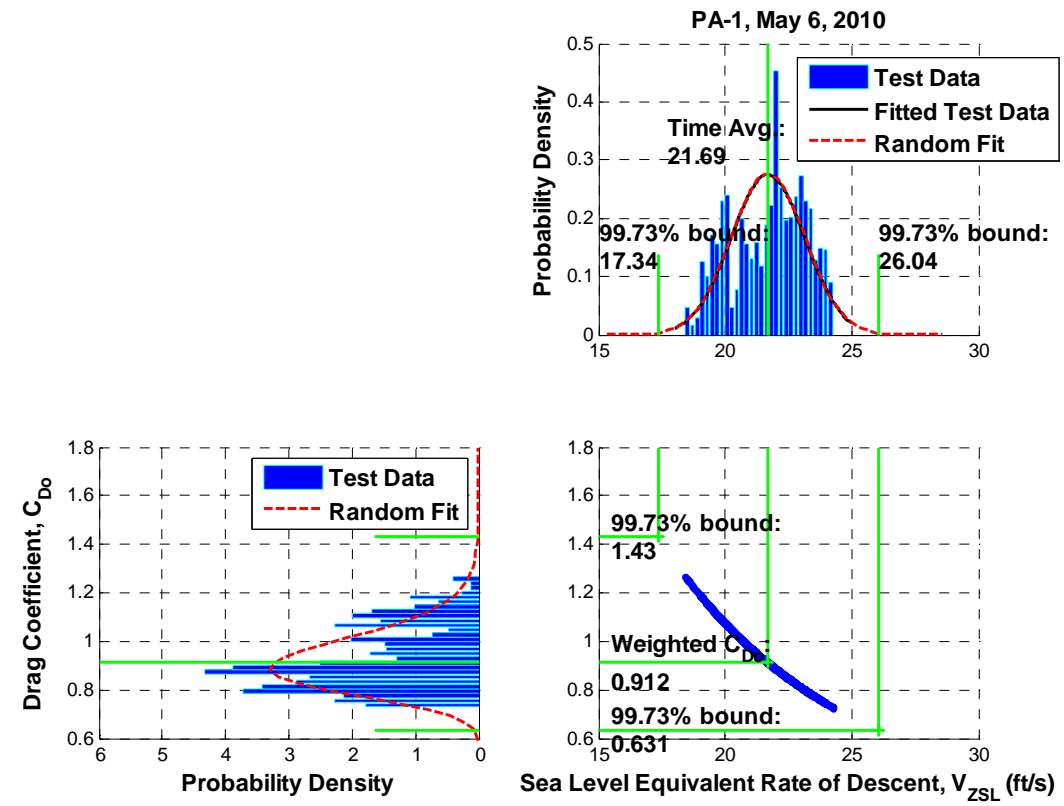

Figure 28. PA-1 steady-state performance histograms. 


\section{Conclusion}

A summary of all time averaged CPAS baseline Mains cluster steady-state sea level equivalent rate of descent test data is presented as a function of canopy loading in Figure 28. Horizontal error bars are due to uncertainty of determining the test vehicle suspended weight. Vertical error bars at the data points indicate the average $\mathrm{V}_{\mathrm{Z}_{\mathrm{SL}}}$ uncertainty for the given test. The minimum and maximum encountered values of steady-state $\mathrm{V}_{\mathrm{Z}_{\mathrm{SL}}}$ are also plotted, as well as estimated $3 \sigma$ dispersion envelopes. A second order polynomial curve fit was used to fit the time averaged data as a function of canopy loading.

It is obvious from the data that the possible rate of descent may vary considerably at splashdown due to the complexity of cluster interaction and atmospheric anomalies. However, the curve fit, reproduced in Eq. (19), can be

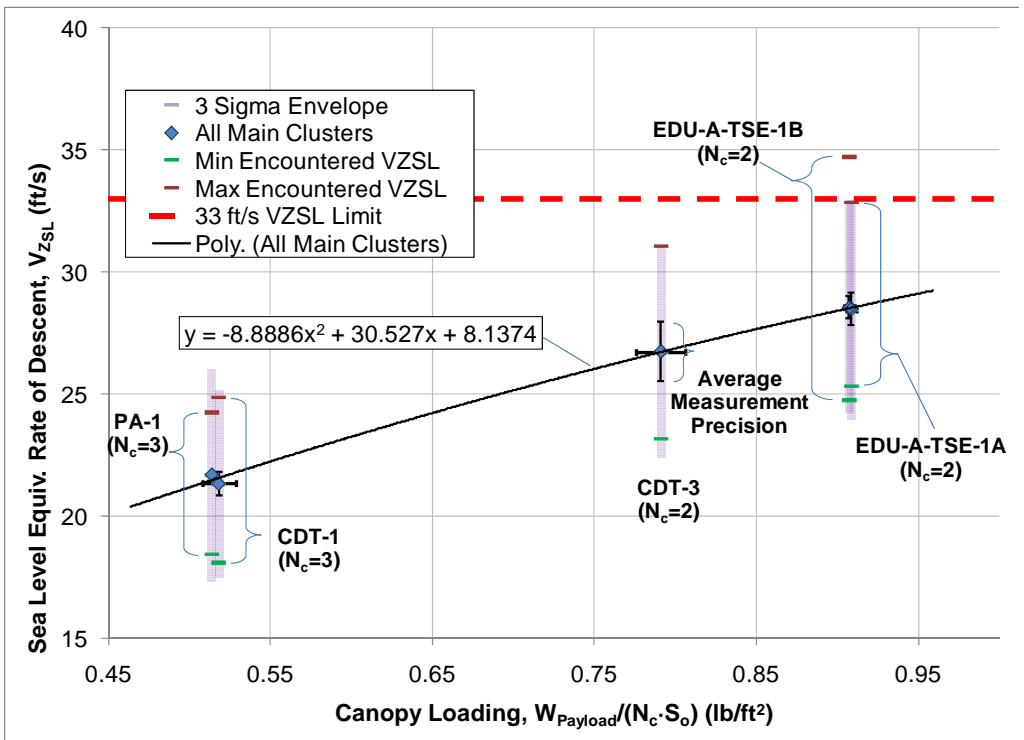

Figure 29. Cluster of Mains Flight Test Steady-State Summary. used as a predictive tool for the baseline design. Equivalent rate of descent appears to have a Gaussian distribution, so the vertical velocity at splashdown may be modeled from Monte Carlo simulations using a random Gaussian distribution centered on the nominal. The average standard deviation $(1 \sigma)$ from all four cluster tests of $1.40 \mathrm{ft} / \mathrm{s}$ is recommended to define the distribution. Note that this equation only models the vertical velocity, so high winds may increase the resultant total landing velocity.

$$
\mathrm{V}_{\mathrm{Z}_{\mathrm{SL}}}=-8.8886 \cdot\left(\frac{\mathrm{W}_{\text {Payload }}}{\mathrm{N}_{\mathrm{c}} \cdot \mathrm{S}_{\mathrm{o}}}\right)^{2}+30.527 \cdot\left(\frac{\mathrm{W}_{\text {Payload }}}{\mathrm{N}_{\mathrm{c}} \cdot \mathrm{S}_{\mathrm{o}}}\right)+8.1374
$$

At the heavier canopy loading, the rate of descent is likely to approach or break the limit for two Mains of the current design. Therefore, further CPAS tests focused on changing the Main parachute design for improved cluster stability. This was done by increasing the geometric porosity and lengthening the suspension lines. Further tests may possibly use a combination of the two.

\section{Acknowledgments}

The author wishes to acknowledge the work of Dr. Vladimir Drozd for characterizing the cluster interaction modes and how these affect measurements. Considerable insight into parachute dynamics was gained from cooperation with the Team for Advanced Flow Simulation and Modeling (T*AFSM) headquartered at the Department of Mechanical Engineering and Materials Science of Rice University in Houston, Texas, and led by Professor Tayfun Tezduyar. Photogrammetric analysis was performed by David Bretz and Sean Duvall of the KX Image Science and Analysis Group. The amount of intense manual effort should be acknowledged as well their development of novel new methods to obtain quality data from limited information. Subsequent CPAS parachute tests are taking full advantage of the techniques pioneered by these groups.

\section{References}

1. Wheeler, Anthony J. and Ganji, Ahmad R. Introduction to Engineering Experimentation. 1996. Prentice-Hall, Inc.

2. Fraczek, Witold. Mean Sea Level, GPS, and the Geoid. Esri corporate web site. [Online] July to September 2003. [Cited: August 16, 2010.] http://www.esri.com/news/arcuser/0703/geoid1of3.html. 
3. National Geodetic Survey. PC Software Download - GEOID09. [Online] March 19, 2010. [Cited: March 29, 2010.] http://www.ngs.noaa.gov/PC_PROD/GEOID09/.

4. Misra, Pratap and Enge, Per. Global Positioning System: Signals, Measurements, and Performance, Second Edition. Lincoln, MA : Ganga-Jamuna Press, 2006. ISBN 0-9709544-1-7.

5. CEACT Information Systems. GPS Compass Solutions: Application -vs- Accuracy. CEACT corporate web site. [Online] September 13, 2006. [Cited: August 17, 2010.] http://www.ceact.com/GPS\%20Compass\%20Accuracy.pdf. 6. NovAtel, Inc., Waypoint Products Group. GrafNav/GrafNet Training Course. May 4 - 5, 2010.

7. NovAtel, Inc. Superstar II. Novatel, Inc. web site. [Online] 2006. [Cited: March 18, 2010.] http://www.novatel.com/Documents/Papers/SUPERSTAR.pdf.

8. Tiaden, Ryan D. and Yakimenko, Oleg A. Development of a Payload Derived Position Acquisition System for Parachute Recovery Systems. August 18-21, 2008. AIAA Guidance, Navigation and Control Conference and Exhibit, Honolulu, HI. AIAA paper 2008-7487.

9. NovAtel, Inc., Waypoint Products Group. Inertial Explorer Training. May 6, 2010.

10. Tiaden, Ryan D. and Yakimenko, Oleg A. Concept Refinement of a Payload Derived Position Acquisition System for Parachute Recovery Systems. May 4 - 7, 2009. 20th AIAA Aerodynamic Decelerator Systems Technology Conference and Seminar, Seattle, WA. AIAA paper 2009-2948.

11. NovAtel, Inc. IMU-HG. NovAtel, Inc. web site. [Online] 2009. [Cited: August 18, 2010.] http://www.novatel.com/assets/Documents/Papers/HG1700_SPAN58.pdf.

12. - . SPAN-SE. NovAtel, Inc. web site. [Online] February 2010. [Cited: March 23, 2010.] http://novatel.com/Documents/Papers/SPAN-SE.pdf.

13. Crossbow Technology, Inc. NAV440 Data Sheet. Crossbow Technology, Inc. web site. [Online] 2010. [Cited: March 18, 2010.] http://www.xbow.com/products/product_pdf_files/inertial_pdf/nav440_datasheet.pdf.

14. Rogers, Jeffrey D. Comparative Analysis Involving Wind Profile Data Sources. May 4-7, 2009. Vols. 20th AIAA Aerodynamic Decelerator Systems Technology Conference and Seminar, Seattle, Washington. AIAA paper 2009-2960.

15. Bledsoe, Kristin, Englert, Megan, Morris, Aaron, and Olmstead, Randy. Overview of the Crew Exploration Vehicle Parachute Assembly System (CPAS) Generation I Main and Cluster Development Test Results. May 4 - 7, 2009. 20th AIAA Aerodynamic Decelerator Systems Technology Conference and Seminar, Seattle, Washington. AIAA paper 2009-2940.

16. Friare, Usbaldo, Jr., et. al. Summary of CPAS Gen II Parachute Performance. May 23 - 26, 2011. 21st AIAA Aerodynamic Decelerator Systems Technology Conference and Seminar, Dublin, Ireland. (Submitted for publication).

17. Idicula, Jinu, et al. A Flight Dynamics Perspective of the Orion Pad Abort One Flight Test. August 10-13, 2009. AIAA Atmospheric Flight Mechanics Conference, Chicago, Illinois. AIAA paper 2009-5730.

18. Stombaugh, Timothy S. and Clement, Brian R. Unraveling the GPS Mystery. Ohio State University web site. [Online] [Cited: August 17, 2010.] http://ohioline.osu.edu/aex-fact/0560.html. 